\title{
ESTUDO EXPLORATÓRIO DE OPINIÕES DE MÃES SOBRE A SAÚDE DAS CRIANÇAS MENORES DE 5 ANOS" *
}

\author{
Débora Falleiros de Mello ** \\ Maria das Graças Carvalho Ferriani **
}

MELLO, D.F. de; FERRIANI, M.G.C. Estudo exploratório de opiniões de mães sobre a saúde das crianças menores de 5 anos. Rev.latino-amenfermagem, Ribeirão Preto, v. 4, n. 2, p. 87-100, julho 1996

O presente estudo apresenta um levantamento de opiniões, sobre alguns aspectos de saúde da criança, através de entrevistas domiciliares, junto às mães de crianças de 0 a 59 meses de idade, residentes em bairros periféricos do Município de Ribeirão Preto. Foi possível evidenciar características sócio-econômicas desse segmento da população e, principalmente, as falas das mães, pontuando aspectos relativos às doenças na infância, cuidados gerais com os filhos, distribuição de tíquetes de leite, vacinação e o processo de crescimento e desenvolvimento da criança. As opiniões das mães relatam episódios de doenças, seus sinais e sintomas e quais cuidados executam, além de apontarem critérios de inclusão-exclusão do programa de suplementação alimentar e aspectos da utilização da atividade de vacinação na Unidade Básica de Saúde Local, trazendo elementos que podem contribuir para a reflexão sobre a atenção à criança, na rede básica de saúde, em Ribeirão Preto.

UNITERMOS: assistência primária, saúde da criança

\section{INTRODUÇÃO}

O setor saúde, no Brasil, sofreu várias transformações nos últimos anos, tendo como política atual o Sistema Único de Saúde (SUS). De um modo geral, a

\footnotetext{
* Este trabalho é parte da Dissertação de MELLO, D. F. Opiniões de mães sobre a assistência à saúde da criança de 0 a 59 meses de idade - um estudo em dois bairros em Ribeirão Preto - SP. Ribeirão Preto, 1993, 104 p. Dissertação (Mestrado) - Escola de Enfermagem de Ribeirão Preto da Universidade de São Paulo

** Docentes do Departamento de Enfermagem Materno-Infantil e Saúde Pública da Escola de Enfermagem de Ribeirão Preto da Universidade de São Paulo
} 
atenção primária à saúde da criança, com vistas à população de menores de 5 anos de idade, tem como objetivo as ações básicas de acompanhamento do crescimento e desenvolvimento, aleitamento materno, imunização, assistência e controle das infecções respiratórias agudas e o controle das doenças diarréicas (BRASIL, 1984). Essas ações foram embasadas nas políticas de expansão e consolidação da rede de serviços básicos de saúde.

A assistência à saúde como um direito tem sido amplamente discutida, dentro das propostas de democratização e participação da população. Conhecer e valorizar as opiniões trazidas pela comunidade implica em ampliar a compreensão, por parte dos profissionais de saúde e da própria população, de valores, conflitos e/ou contradições acerca das condições de saúde (LEAL et al., 1990).

Vários aspectos são apontados, considerando o ponto de vista da população usuária, sendo relevantes às opiniões em termos da avaliação da assistência médica, para fornecer elementos ao planejamento, à administração e à avaliação dos serviços prestados (ROCHA et al., 1986). Outros estudos abordam as necessidades de saúde fundamentadas nos níveis e estrutura de morbidade da população, trazendo levantamentos domiciliares sobre a ocorrência e a percepção da doença e suas relações com a utilização dos serviços de saúde (MEDICI, 1990; SIMÕES, 1989; ROCHA \& NOGUEIRA, 1985).

Neste estudo, questiona-se como as mães percebem a assistência às crianças, quais as doenças infantis vivenciadas e como elas apresentam os aspectos do crescimento infantil. Destaca-se o interesse em levantar alguns aspectos da saúde da criança, do ponto de vista das mães, identificando suas opiniões sobre os cuidados com os filhos.

Para tanto, foi realizado um levantamento de opiniões junto às mães de crianças menores de 5 anos de idade, residentes nos bairros D. Mielle e Parque das Andorinhas do município de Ribeirão Preto, apresentando características sócio-econômicas da população entrevistada e aspectos sobre doenças na infância, cuidados gerais com os filhos, distribuição de tíquetes de leite, vacinação e crescimento das crianças.

\section{METODOLOGIA}

Este levantamento configura um estudo descritivo exploratório, que procura expor algumas características sócio-econômicas e opiniões das mães entrevistadas, entendendo que as falas podem retratar, em parte, a experiência do dia-a-dia no cuidado à saúde da criança, expressas através do senso comum e constituem-se em uma forma de representação, contendo aspectos ligados ao processo saúde-doença, a alguma situação de vida ou a uma idéia sobre as instituições. 
A investigação baseou-se em entrevistas domiciliares semi-estruturadas, aplicadas em uma amostra selecionada, sendo utilizado alguns pontos do método de amostragem por conglomerado (CARVALHEIRO \& SANCHES, 1979; SANCHES, 1985).

Nesse estudo, o conglomerado constituiu-se de uma quadra ou quarteirão, ou seja, um conjunto de domicílios. Inicialmente, foram enumeradas todas as quadras existentes nos dois bairros escolhidos, procedendo ao sorteio de $20 \%$ delas, correspondendo a aproximadamente 13 quadras sorteadas, as quais foram percorridas e nelas entrevistadas todas as mães com filhos menores de 5 anos de idade. No período de junho a agosto de 1992 foram entrevistadas 80 mães de crianças nessa faixa etária.

A escolha desses bairros para a realização da pesquisa de campo refere-se, principalmente, à nossa experiência profissional na Unidade Básica de Saúde Local em período anterior, revelando nosso interesse em aprofundar o conhecimento sobre a população de mães de crianças menores de 5 anos de idade, nos aspectos ligados à saúde da criança.

Estes bairros localizam-se no setor oeste do município de Ribeirão Preto, são bem próximos e, de um modo geral, não apresentam diferenças entre si. São consideradas áreas urbanas periférícas e possuem como características gerais, em toda a sua extensão, ruas asfaltadas; energia elétrica; rede de água e esgoto; coleta de lixo; casas de alvenaria; estabelecimentos comerciais; uma Escola Infantil Municipal; uma Escola Estadual de $1^{\circ}$ Grau e uma Unidade Básica de Saúde da Rede Municipal. A população estimada para a área de abrangência dessa unidade de saúde, no ano de 1992, era de 8.817 habitantes.

Para o trabalho de campo, foi elaborado um roteiro para a entrevista, constando de uma parte inicial, com as características sócio-econômicas (idade da mãe e das crianças; situação de trabalho e escolaridade do pai e da mãe; renda familiar; número de moradores no domicílio e tempo de moradia no bairro); e de uma segunda parte, com perguntas abertas sobre doenças na infância, cuidados gerais com os filhos, distribuição de tickets de leite; vacinação e aspectos do crescimento e desenvolvimento.

Considerando o objetivo traçado, a análise deste trabalho buscou apresentar as visões das mães através do agrupamento em quatro núcleos temáticos, visando uma primeira aproximação para o entendimento das opiniões das mães e apontando as falas mais relevantes expressas nas entrevistas. Esses núcleos temáticos estão especificados a seguir:

Doenças na Infância: refere-se aos episódios de doenças e as internações no último ano, que as mães se lembram no cuidado à saúde de seus filhos.

Cuidados Gerais: busca apreender quais as ações de saúde realizadas pelas mães durante as doenças que os filhos apresentaram no último ano.

Utilização da Unidade Básica de Saúde Local: compreende a utilização da unidade de saúde do bairro para: 
- Programa de Distribuição de Tíquetes de Leite Fluido: identificando a inscrição das crianças no programa e as opiniões das mães sobre a distribuição nos postos de saúde.

- Vacinação: identificando se as crianças possuem carteira de vacinação e em que época as mães utilizam o posto para vacinar.

Crescimento Infantil: aborda o que as mães colocam como importante para as crianças crescerem bem.

\section{RESULTADOS E DISCUSSÃO}

Inicialmente são apresentados os dados sócio-econômicos, constituindo uma caracterização geral da população entrevistada.

Com relação à idade das mães encontrou-se uma amplitude de variação de 16 a 46 anos, sendo $46,2 \%$ na faixa etária de 20 a 29 anos e $45,0 \%$ de 30 a 40 anos.

Nesta amostra domiciliar, foram encontradas 98 crianças menores de 5 anos, sendo 25,5\% menores de 1 ano e 74,5\% entre 1 a 4 anos, 11 meses e 29 dias.

Na Tabela 1 apresenta-se a situação de trabalho do pai e da mãe, isto é, a atividade no momento: se está trabalhando, desempregado ou aposentado. Verifica-se o predomínio de mães que trabalham no lar $(63,8 \%)$, seguidas por aquelas que trabalham fora do lar $(33,8 \%)$. Esses dados podem indicar que, geralmente, é a mãe quem está cuidando dos seus filhos no lar. Verifica-se ainda, que $12,5 \%$ das mães trabalham sem carteira assinada; se compararmos aos homens (pai da criança), com $1,2 \%$,chega a ser dez vezes maior. Em relação ao pai, o trabalho é exercido em sua maioria com carteira de trabalho assinada $(53,8 \%)$ e existe um número expressivo de trabalhadores autônomos $(35,0 \%)$.

TABELA 01 - DISTRIBUIÇÃO DA FREQÜÊNCIA DOS PAIS E DAS MÃES, SEGUNDO A SITUAÇÃO DE TRABALHO, BAIRROS D. MIELLE E PARQUE DAS ANDORINHAS, RIBEIRÃO PRETO, 1992

\begin{tabular}{lcccc}
\hline \multirow{2}{*}{ Situação de Trabalho } & \multicolumn{2}{c}{ PAI } & \multicolumn{2}{c}{ MÃE } \\
\hline Trabalho no lar & N & $\%$ & N & $\%$ \\
Autônomo & - & - & 51 & 63,8 \\
Com carteira de trabalho & 28 & 35,0 & 06 & 7,5 \\
Sem carteira de trabalho & 43 & 53,8 & 11 & 13,8 \\
Desemprego & 01 & 1,2 & 10 & 12,5 \\
Sem informações & - & - & 01 & 1,2 \\
\hline Total & 08 & 10,0 & 01 & 1,2 \\
\hline
\end{tabular}


O trabalho da mulher e a criação dos filhos são questões discutidas em vários âmbitos da sociedade e entende-se que somente o fato da mulher trabalhar fora ou no lar não traduz toda a dimensão da educação e do envolvimento dos pais com a criação dos filhos.

Outra característica levantada foi a renda familiar, expressa na tabela 2. Observa-se que $42,5 \%$ das famílias têm rendimentos mensais entre 2 a 5 salários mínimos, 31,2\% entre 5 a 10 salários mínimos, 12,5\% com até 2 salários mínimos e $10 \%$ com mais de 10 salários mínimos. Os dados sem informação relacionam-se ao fato de três mães $(3,8 \%)$ não saberem ou não desejarem expressar os rendimentos. De um modo geral, observa-se que as famílias participam do mercado de trabalho e, portanto, tem possibilidades de obter algum rendimento para sua sobrevivência e de seus filhos.

Neste levantamento, as famílias com até 4 pessoas perfazem $53,8 \%$ do total de domicílios entrevistados, aquelas com 5 a 7 pessoas $41,2 \%$ e o restante, 5\%, corresponde às famílias compostas por 8 pessoas e mais. Com relação ao número de crianças, observa-se que $97,5 \%$ das famílias têm de 1 a 2 filhos na faixa etária de 0 a 59 meses.

TABELA 02 - DISTRIBUIÇÃO DA RENDA FAMILIAR MENSAL EM SALÁRIOS MÍNIMOS, BAIRROS D. MIELLE E PARQUE DAS ANDORINHAS, 1992

\begin{tabular}{ccc}
\hline Renda Familiar & N & $\%$ \\
\hline 0 a 2 & 10 & 12,5 \\
2 a 5 & 34 & 42,5 \\
5 a 10 & 25 & 31,5 \\
10 e mais & 08 & 10,0 \\
Sem informação & 03 & 3,8 \\
\hline TOTAL & $\mathbf{8 0}$ & $\mathbf{1 0 0 , 0}$ \\
\hline
\end{tabular}

* Salário mínimo na época $=$ Cr\$230.000,00

Quanto às pessoas que contribuem para a renda familiar, constata-se que, na maioria das famílias, é uma pessoa $(57,5 \%)$ que trabalha fora, geralmente o pai; existem, porém, famílias em que há duas (27,5\%), três (10,0\%), quatro $(2,5 \%)$ ou cinco $(2,5 \%)$ pessoas trabalhando fora, dentre eles estão as mães, avô, tios e sobrinhos. Optou-se pela utilização da renda familiar por subentender que traria uma idéia geral da família quanto aos rendimentos.

Trata-se de um segmento da população inserido em processos concretos de trabalho, podendo caracterizar, de certa forma, os níveis de consumo e, portanto, o acesso a bens materiais através de seus rendimentos (VICTORA et al.,1990). Compreende-se que o tamanho das famílias e a inserção dos seus membros no mercado de trabalho estão associados à situação sócio-econômica. O fato desse grupo de famílias possuir vínculo empregatício e grande parte com rendimentos acima de 2 salários mínimos oferece melhores condições de vida em contraposição às famílias em situação de pobreza e desemprego.

Rev. Latino Am. Enf. - Ribeirão Preto - v. 4 - n. 2 - p. 87-100 - julho 1996 
Os dados sobre escolaridade do pai e da mãe são apresentados na tabela 3. Observa-se que $46,3 \%$ das mães têm o $1^{\circ}$ grau incompleto, em seguida o $2^{\circ}$ grau completo $(17,5 \%), 1^{\circ}$ grau completo $(16,3 \%)$ e curso universitário $(10,0 \%)$. O pai apresenta porcentagens iguais para $1^{\circ}$ grau incompleto $(32,5 \%)$ e em seguida o $1^{\circ}$ grau completo (12,5\%). Algumas mães (11,2\%) não souberam informar a escolaridade do pai das crianças, no momento da entrevista.

TABELA 03. DISTRIBUIÇÃO DA FREQÜÊNCIA DOS PAIS E DAS MÃES, SEGUNDO O GRAU DE INSTRUÇÃO, BAIRROS D. MIELLE E PARQUE DAS ANDORINHAS, RIBEIRÃO PRETO, 1992

\begin{tabular}{lcccc}
\hline \multirow{2}{*}{ Escolaridade } & \multicolumn{2}{c}{ PAI } & \multicolumn{2}{c}{ MÃE } \\
& N & $\%$ & N & $\%$ \\
\hline Nenhuma & - & - & - & - \\
$1^{\circ}$ grau incompleto & 26 & 32,5 & 37 & 46,3 \\
$1^{\circ}$ grau completo & 10 & 12,5 & 13 & 16,3 \\
$2^{\circ}$ grau incompleto & 03 & 3,8 & 06 & 7,5 \\
$2^{\circ}$ grau completo & 26 & 32,5 & 14 & 17,5 \\
Universitário incompleto & 03 & 3,8 & 01 & 1,2 \\
Universitário completo & 03 & 3,8 & 08 & 10,0 \\
Sem informações & 09 & 11,2 & 01 & 1,2 \\
\hline TOTAL & $\mathbf{8 0}$ & $\mathbf{1 0 0 , 0}$ & $\mathbf{8 0}$ & $\mathbf{1 0 0 , 0}$ \\
\hline
\end{tabular}

A escolaridade, principalmente da mãe, é um aspecto sempre levantado nos estudos da área de saúde materno-infantil, pois pode estar relacionada com o grau de envolvimento que a mãe e/ou o pai tem com a educação dos filhos, com o conhecimento sobre os cuidados com a saúde e os mecanismos de prevenção das doenças, bem como permitir à população maior acesso aos bens e serviços da sociedade, às informações, com questionamentos sobre a situação social, os direitos e participação (VICTORA et al., 1990). Nesse sentido, acredita-se que níveis de instrução mais altos, assim como os de renda, possibilitam às mulheres maior acesso aos serviços de saúde e informações em geral, permitindo-lhes cuidar da saúde dos filhos e da sua própria saúde. Ressalvas sejam feitas para o fato de que neste estudo não estabelecemos uma estreita correlação entre os níveis de escolaridade, renda familiar, trabalho e as opiniões das mães entrevistadas.

Outro ponto levantado na entrevista foi o tempo de moradia das famílias nos bairros em estudo. Averiguou-se que $48,8 \%$ das famílias residem de 5 a 10 anos no local; $25,0 \%$ residem de 2 a 5 anos e $26,3 \%$ há menos de 2 anos. As condições de habitação desses bairros é praticamente homogênea no que se refere ao tipo de construção das casas (alvenaria) e à existência de rede de água e esgoto em toda a sua extensão; há boa ventilação nas casas e não há favelas no local. 
Nesse estudo buscou-se apresentar, de forma breve, um perfil com estas características sócio-econômicas, sem estabelecer variações por níveis ou categorizar em classes sociais, para tal fim impõe-se um detalhamento maior da caracterização da clientela.

Os dados sobre saneamento básico, vínculo empregatício, renda familiar permeando entre 2 a 5 e 5 a 10 salários mínimos, e determinados níveis de escolaridade, apontam características de um segmento da população em boas condições de existência, quando comparado às populações marginalizadas da sociedade, não estando exposto à determinadas doenças geradas em situações de extrema carência. A expectativa é de que as crianças cresçam saudáveis, ou pelo menos, sem intercorrências causadas pela miséria.

Em relação aos núcleos temáticos elaborados, o primeiro deles é Doenças na Infância e refere-se as intercorrências clínicas das crianças menores de 5 anos de idade, ocorridas nos últimos doze meses, bem como dados de internações.

Os dados apresentados na Tabela 4 constituem os diagnósticos referidos pelas mães sobre os episódios de doenças dos seus filhos neste período. Nesse levantamento domiciliar são considerados dados de morbidade referida pela população investigada.

TABELA 04. INTERCORRÊNCIAS CLÍNICAS NAS CRIANÇAS DE 0 A 59 MESES, OCORRIDAS NOS ÚLTIMOS 12 MESES, BAIRROS D. MIELLE E PARQUE DAS ANDORINHAS, RIBEIRÃO PRETO, 1992

\begin{tabular}{lcc}
\hline Intercorrências Clínicas & N & \% \\
\hline Gripe & 76 & 61,29 \\
Bronquite & 09 & 7,26 \\
Pneumonia & 07 & 5,64 \\
Alergia Respiratória & 08 & 6,45 \\
Otite & 10 & 8,06 \\
Diarréia & 03 & 2,42 \\
Hepatite & 01 & 0,81 \\
Rubéola & 04 & 3,22 \\
Catapora & 02 & 1,61 \\
Caxumba & 01 & 0,81 \\
Verminose & 01 & 0,81 \\
Infecção Urinária & 01 & 0,81 \\
Constipação Intestinal & 01 & 0,81 \\
\hline TOTAL & $\mathbf{1 2 4}$ & $\mathbf{1 0 0 , 0}$ \\
\hline
\end{tabular}


Nota-se que a maioria (apesar de no total serem apenas quatro) das enfermidades mencionadas pelas mães é do grupo de doenças do aparelho respiratório $(80,7 \%)$, o que vai de encontro aos dados da literatura. Vários estudos apontam as doenças respiratórias agudas como a principal causa de demanda aos serviços de saúde e, geralmente, aparecem associadas ao aspecto nutricional (FUNDAÇÃO IBGE, 1992; MONTEIRO, 1988).

A faixa etária tem grande importância na presença da doença respiratória, sendo as crianças mais novas, as mais atingidas, e nas demandas aos serviços de saúde, em vários contextos sócio-econômicos, as freqüências encontradas vão de 4 a 8 episódios de doença respiratória por criança ao ano, em menores de 5 anos de idade. (MONTEIRO, 1988)

As enfermidades ocorridas no período investigado, nesse estudo, constituem-se apenas na somatória de casos ocorridos que a mãe se lembrou, no momento da entrevista. O fato de serem investigadas as intercorrências clínicas, no período dos últimos doze meses, acaba selecionando as doenças mais importantes e/ou mais graves, por ser um período recordatório longo, porém a intenção é retratar o que a mãe coloca, de certa forma, como relevante nestas intercorrências, para cuidar de seus filhos.

Em relação às internações, foram evidenciadas pelas mães como momentos marcantes nos cuidados com os filhos; elas se lembram com clareza e relatam a causa da internação. Das crianças que fizeram parte da amostra, apenas 07 foram internadas nos últimos doze meses, apresentando: 01 desidratação, 01 hepatite, 01 meningite, 02 cirurgias (de ortopedia) e 02 pneumonias.

Os Cuidados Gerais com os filhos constituem o segundo núcleo temático. Ele está relacionado ao anterior e busca retrataras ações que a mãe executou, diante de determinadas enfermidades apresentadas pelas crianças.

Quando a mãe menciona que a criança apresentou alguma doença, nota-se que ela observou sinais e sintomas como: "nariz escorrendo", "febre", "falta de apetite", "tosse", "dor na barriga", entre outras; fazendo uma "avaliação de mãe" e o sinal que ela separa para levar a criança ao médico é a febre. Se a criança não está apresentando febre ela prepara soluções caseiras (chás, mel com limão, sucos, alguns anti-térmicos) e não procura assistência médica.

Quando há presença de febre distinguem-se aquelas mães que utilizam a medicação já prescrita em outra ocasião, usam antitérmicos, remédios caseiros e também levam ao médico, como nestas expressões:

"Faço vaporização, dou chás, xarope caseiro, pingo soro no nariz e se piorar levo ao médico";

"O médico receita AAS, então quando ela tem gripe dou um AAS infantil";

"Dou chá de puejo, vaporização e, quando dá febre, levo ao médico"

$E$ também aquelas mães que levam os filhos imediatamente ao médico:

"Eu não gosto de fazer nada, prefiro levar ao médico";

"Levo ao médico, nunca dou medicação sem saber o que ele tem". 
Compreende-se que estas mães percebem sinais de certas doenças que acometem seus filhos, possuindo algumas noções sobre hidratação, alimentação, algumas medicações antitérmicas, entre outras. Na maioria das vezes, estas atitudes estão ligadas às experiências anteriores com a criação dos filhos mais velhos, com pessoas da família e vizinhos; acrescenta-se também a questão da escolaridade, permitindo o acesso às informações e o conhecimento dos cuidados e sinais de certas doenças. Observa-se que existe um aspecto forte norteando a mãe no cuidado com a criança doente, ou seja, esta elege um critério para tomar a conduta de levar a criança ao médico. A febre costuma ser este indicador, orientando as mães na decisão de procurar assistência médica.

Para BOLTANSKI (1989), “... as mães guiam-se pelo comportamento da criança manhosa, calma demais ou cansada, pelo apetite, ou em função das dores de que ela se queixa. Mas esses sinais são apenas secundários, e é a febre que constitui para as mães o sintoma mais claro de doença". O autor também coloca o uso dos remédios pelas mães, enfatizando que elas possuem remédios conhecidos, compondo uma "farmácia familiar". A "medicina familiar", segundo este autor, é considerada imitativa, ou seja, as mães reproduzem gestos e palavras dos médicos, memorizando alguns medicamentos, sintomas e nomes de doenças. Esses aspectos estão relacionados com o processo de medicalização da atenção à saúde; observa-se que a mãe valoriza, sobremaneira, a terapêutica medicamentosa.

Trazendo o terceiro núcleo temático sobre a Utilização da Unidade Básica de Saúde Local, inicialmente são apresentados aspectos sobre a distribuição de tíquetes de leite fluido nas unidades.

O levantamento mostra que $88,8 \%$ das crianças desta amostra não estão inscritos no programa, e apenas um contingente de $11,2 \%$ encontra-se cadastradas nesse programa.

Outro aspecto explorado foi a opinião das mães frente à distribuição de leite. A maioria das mães que não tinham crianças inscritas no programa limitou-se a responder somente "não", sem demonstrar outras opiniões. No entanto, algumas mães, tanto aquelas que têm como aquelas que não tem filhos inscritos no programa de leite, levantaram dois aspectos: um relacionado à questão financeira da família, mencionando que o leite ajuda e está custando muito caro e outro que aponta o parâmetro biológico, alegando, primeiramente, o peso baixo da criança como critério para a inscrição nos programas de leite, mas também expressaram o beneficio que 0 leite traria no aspecto financeiro. Houve quatro mães que referiram a importância da amamentação para a alimentação e crescimento da criança.

Observa-se que poucas mães desta amostra recebem leite e uma parcela não está satisfeita com o critério estabelecido para inscrição no programa de distribuição de leite na Unidade Básica, conforme expressões apresentadas a seguir:

"Acho que não devia ser só para desnutridos, tem gente que tem dificuldade financeira e precisa"; 
"Eu pego leite, acho muito bom, ajuda muito para a gente que precisa, a gente paga aluguel, tanta coisa, já facilita, o leite está caro".

Percebe-se que as mães conhecem o critério de inclusão-exclusão do Programa de Suplementação Alimentar da Secretaria Estadual de São Paulo, adotado pela Secretaria Municipal de saúde de Ribeirão Preto, porém, parecem concordarem com a sua finalidade: a recuperação da criança desnutrida ou em risco de desnutrir-se (PAMPLONA, 1989). Destaca-se que não é somente uma questão nutricional, mas envolve aspectos sócio-econômicos e configura uma reivindicação. Vários pontos dos programas de alimentação e nutrição infantil já foram analisados em outros estudos, discutindo, entre outras questões a baixa cobertura havendo problemas em relação ao impacto sobre o estado nutricional e os critérios utilizados (FUNDAÇÃO IBGE, 1992; MONTEIRO, 1988).

Ainda com relação à Utilização da Unidade Básica de Saúde Local, foi investigado sobre a utilização da atividade de vacinação se as crianças possuem carteira de vacinação e em que época as mães as levam para vacinar.

As mães responderam que todas as crianças possuem carteira de vacinação e afirmaram que levam para vacinar nas datas marcadas e nas campanhas de vacinação:

"Tem carteirinha, levo na data certa das cadernetas e nas campanhas, agora só com 5 anos";

"Ela tem, eu faço o calendário completo, levando nos retornos"; "Tem, levo todas as vezes que tem retorno marcado e nas campanhas".

De certa forma, as mães emitem um conhecimento a respeito da vacinação, conforme o calendário vacinal. Este aspecto pode indicar que é vacinação constitui uma das preocupações no cuidado à saúde da criança; as informações que elas trazem são importantes e elas vêem a unidade básica de saúde com resolutividade neste aspecto.

As normas e o calendário vacinal foram colocados em prática e difundidos nos estados e municípios, segundo as diretrizes do Programa Nutricional de Imunizações, visando à extensão da cobertura vacinal, conforme as estratégias das ações básicas de saúde. (BRASIL, 1984) A imunização é considerada por uma atividade quase que exclusiva do serviço público; atualmente, em Ribeirão Preto, a maioria das crianças que procuram por vacinação, utiliza a rede básica de serviços públicos de saúde.

Quanto ao quarto núcleo temático, Crescimento Infantil, foram abordados aspectos do crescimento e desenvolvimento das crianças menores de 5 anos, retratando o que as mães colocam como importante para as crianças crescerem bem. As respostas apresentadas abaixo evidenciam as preocupações das mães:

"Acima de tudo é alimentação, com boa alimentação a criança desenvolve, e não tem problema de saúde";

"É uma boa alimentação, os cuidados, a higiene, a limpeza das roupas";

“... cuidados com as doenças para não ficar crônico"; 
"Eu acho que é uma boa alimentação, cuidar e sempre levar ao médico para ele estar avaliando";

"Alimentação boa, educação e relacionamento bom entre os pais"; "Uma boa alimentação, lugar bom para morar, bastante amor e carinho".

Um ponto a ressaltar, como fala mais freqüente, é a alimentação, que parece ser uma forte preocupação que estas mães têm no cuidado à saúde da criança. Depreende-se, pelo menos, dois aspectos para a criança crescer bem, um no âmbito biológico, que enfatiza a alimentação, higiene e assistência médica, e outro no âmbito afetivo, que associa estes aspectos aos fatores de educação dos filhos, amor e relacionamento familiar.

Compreende-se ter sido apontado um conceito de saúde-doença relativamente amplo, pois essas opiniões chegam a explicitar algumas associações às condições de vida, pelo fato de relacionarem a saúde com a alimentação, cuidados de higiene, moradia e educação. Essas associações caracterizam um segmento da população que possui melhores condições de vida, em contrapartida àquelas mães em condições precárias, que não expressam estas associações, levantadas em estudos realizados em outros locais (MINAYO, 1988). Consideram-se extremamente relevantes estas opiniões, estabelecendo conceitos significativos sobre a saúde infantil,

\section{CONSIDERAÇÕES FINAIS}

De acordo com o agrupamento dos núcleos temáticos, verifica-se que as falas das mães expressam preocupações com a criação dos filhos, relatam os episódios de doenças que seus filhos apresentaram, elas percebem sinais e sintomas de certas doenças da infância, executam cuidados e atenção à criança doente e destacam a febre como um forte indicador para tomar a decisão de procurar assistência médica.

No tocante à utilização da Unidade Básica de Saúde Local, referente ao programa de suplementação alimentar, elas conhecem os critérios de inclusão-exclusão das crianças, apontando algumas questões sobre a situação social. Em relação à vacinação, percebe-se que constitui uma ação de saúde importante e que a unidade básica vem resolvendo; a população tem confiança nesse tipo de intervenção do serviço público.

As falas das mães, apontando e relacionando a alimentação, moradia, educação, cuidados higiênicos e aspectos afetivos com o crescimento das crianças, constituem opiniões com valores mais amplos e associações da saúde infantil com as condições de vida. 
Considera-se importante o serviço valorizar a figura da mãe no processo de cuidar das crianças, enquanto aquela que efetivamente presta os cuidados gerais a saúde da criança no dia-a-dia. Os profissionais de saúde necessitam repensar a relação usuário-serviço de saúde, para (re)conhecer as opiniões trazidas pela população e se envolverem com a realidade de saúde e de vida da população adstrita ao serviço.

Compreende-se que as transformações dos serviços de saúde ocorrem em longo prazo, constituindo um desafio organizar o atendimento visando à saúde coletiva, assistência integral e o acesso da população aos bens coletivos.

O presente estudo apresentou um levantamento descritivo, com limitações, pois entende-se que o trabalho com a clientela é complexo, não se constitui somente de abordagens de opiniões, requerendo outras investigações e metodologias que possibilitem um entendimento mais abrangente, visando aproximar da totalidade dessas questões.

\section{AN EXPLORATORY STUDY: OPINIONS OF MOTHERS ON THE HEALTH OF CHILDREN UNDER 5 YEARS OLD}

This study presents opinions of mothers about aspects of children health, 0-59 months, living in suburbs of the city of Ribeirão Preto, using home interviews. Several social-economic characteristics of this population were noted, especially the concerns of mothers related to: childhood disease, general core of their children, distribution of milk tickets, immunization, children's growth and development process. Mothers opinions present concerns about diseases, signs and symptoms, mothers' care, criteria for inclusion-exclusion in the Program of Food Supplementation and aspects about the utilization of the immunization in time Local Basic Health Unit, offering several elements which can contribute to a reflection on the care given to children at the basic level of health services in the city of Ribeirão Preto.

UNITERMS: primary health care, children health

\section{ESTUDIO EXPLORATORIO DE OPINIONES DE MADRES, SOBRE LA SALUD DE NIÑOS MENORES DE 5 AÑOS}

El presente trabajo presenta un levantamiento de opiniones, sobre la salud del niño, realizado con madres de niños de 0 a 59 meses de edad, residentes en barrios periféricos de Ribeirão Preto, a través de entrevistas domiciliarias. Fueron evidenciadas 
características socio-económicas de ese sector de la población y, principalmente, las declaraciones de las madres, apuntando aspectos relativos a las enfermedades en la infancia, cuidados generales con los hijos, distribución de vales de leche, vacunación y el proceso de crecimiento y desarrollo en los niños de esa edad. Las opiniones de las madres relatan los episodios de enfermedades, sus signos y síntomas, los cuidados que ejecutan, indican los criterios de inclusión-excusión del Programa de Suplementación Alimentaría y aspectos le la utilización de la actividad de vacunación en la Unidad Básica de Salud Local, presentando algunos elementos que pueden contribuir para la reflexión sobre la atención al niño, prestada por la red básica de salud en Ribeirão Preto.

TÉRMINOS CLAVES: asistencia primaria salud del niño

\section{REFERÊNCIAS BIBLIOGRÁFICAS}

01. BOLTANSKI, L. As classes sociais e o corpo. Trad. de Regina A. Machado. 3.ed. Rio de Janeiro: Graal, 1989.

02. BRASIL. Ministério da Saúde. Assistência integral à saúde da criança: ações básicas. Brasília: Centro de Documentação do Ministério da Saúde, 1984.

03. CARVALHEIRO, J. da R.; SANCHES, O. Amostragem domiciliar contínua em estudos epidemiológicos e no ensino. São Paulo, Rev. Saúde Públ., v. 13, p. 195-202, 1979.

04. FUNDAÇÃO INSTITUTO BRASILEIRO DE GEOGRAFIA E ESTATÍSTICA. Crianças e adolescentes: indicadores sociais. Rio de Janeiro: IBGE, 1992.

05. LEAL, M.C. et al. Percepção materna da desidratação em crianças com diarréia. Estudo de concordância com diagnóstico médico. Rev.Saúde Públ., São Paulo, v. 24, n. 3, p.196-203, 1990.

06. MEDICI, A.C. Aspectos sócio-econômicos da morbidade no Brasil - uma contribuição aos estudos sobre população e saúde (o caso do Nordeste). São Paulo, Saúde em Debate, n. 30, p. 40-51, dez., 1990.

07. MINAYO, M.C. de S. Avaliação qualitativa da atenção primária à saúde numa favela do Rio de Janeiro (RAP). Rio de Janeiro, 1988. 29 p. (Mimeografado)

08. MONTEIRO, C.A. Saúde e nutrição das crianças de São Paulo: diagnóstico, contrastes sociais e tendências. São Paulo: HUCITEC/EDUSP, 1988.

09. PAMPLONA, V. L. Algumas reflexões sobre o programa de suplementação alimentar: a questão dos critérios de inclusão da população no mesmo. Ribeirão Preto: Escola de Enfermagem de Ribeirão Preto - USP, 1989. 15 p. (Mimeografado). 
10. ROCHA, J.S.Y., NOGUEIRA, J. L. Padrões de morbidade em assistência primária na Região de Ribeirão Preto, SP (Brasil). Rev. Saúde Públ., São Paulo, v. 19, p. 215-24, 1985.

11. ROCHA, J.S.Y. et al. Avaliação de assistência médica baseada na opinião dos pacientes. Medicina, Ribeirão Preto, v. 19, n. 2, p. 89-98, 1986.

12. SANCHES, O. Considerações sobre amostragem. Ribeirão Preto, Escola de Enfermagem de Ribeirão Preto - USP, 1985. 17 p. (Mimeografado)

13. SIMÕES, M.J.S. Morbidade referida e utilização de consulta médica infantil num centro de saúde municipal. Araraquara-SP, 1987. Medicina, Ribeirão Preto, v. 22, n.314, p. 105-115, jul/dez. 1989.

14. VICTORA, C. G. et al. Pobreza e saúde: como medir nível sócio-econômico em estudos epidemiológicos de saúde infantil? In: CONGRESSO BRASILEIRO DE EPIDEMIOLOGIA, 1; Campinas, 1990. Anais. Campinas: ABRASCO/Faculdade de Ciências Médicas da UNICAMP, 1990. p. 302-15. 